\title{
Laryngeal Mucoepidermoid Carcinoma
}

National Cancer Institute

\section{Source}

National Cancer Institute. Laryngeal Mucoepidermoid Carcinoma. NCI Thesaurus. Code C9463.

A rare mucoepidermoid carcinoma of the larynx. It usually arises from the suprag lottic area. Hoarseness and dysphagia are the presenting symptoms. 